\title{
Acute Massive Gastric Dilatation in a Patient with an Eating Disorder
}

\author{
Yuriko Nishiie and Naoyoshi Nagata
}

Key words: gastric distension, gastric necrosis

(Intern Med 57: 2267-2268, 2018)

(DOI: 10.2169/internalmedicine.0576-17)

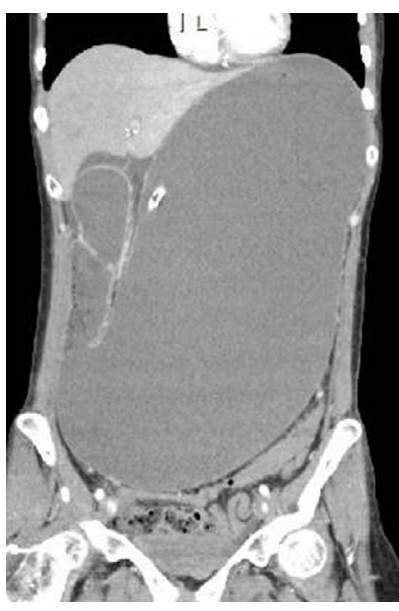

Picture 1.

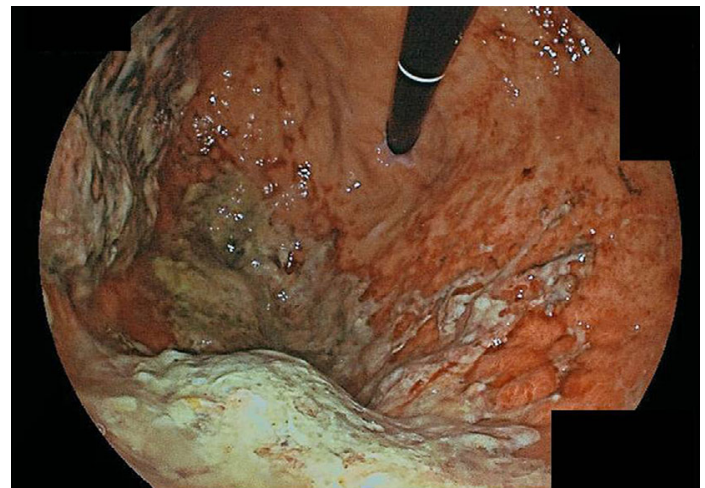

Picture 3.

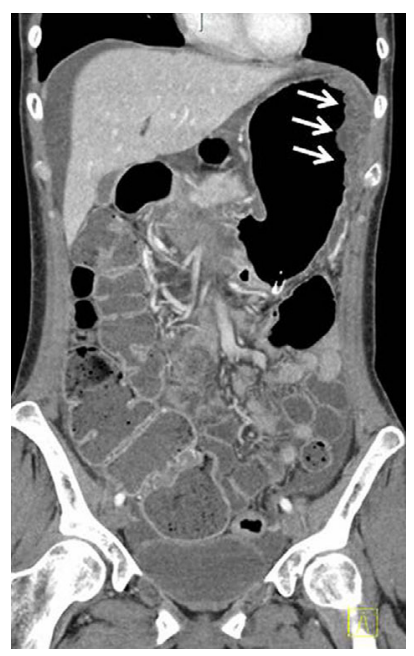

Picture 2.

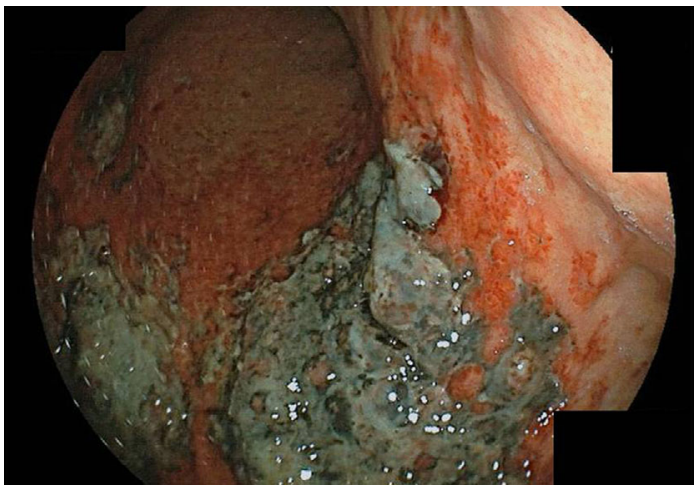

Picture 4.
A 33-year-old woman with an eating disorder and depression was admitted after ingesting large amounts of water. She presented with abdominal distension and tenderness. Abdominal computed tomography (CT) revealed massive gastric distension (Picture 1). A nasogastric tube was inserted for drainage, and $6,000 \mathrm{~mL}$ of fluid was aspirated from the stomach. Three days after gastric decompression, repeat abdominal $\mathrm{CT}$ was performed because of persistent 
abdominal pain. CT showed improvement of the gastric distension and thickened gastric wall (Picture 2). Upper gastrointestinal endoscopy revealed ischemia with areas of gastric mucosal necrosis in the fundus and along the greater curvature (Picture 3, 4). Her abdominal symptoms improved markedly with continued gastric decompression and proton pump inhibitor therapy without gastric surgery. When characteristic findings of massive gastric dilation are noted on CT, with extensive necrotic ulceration on endoscopy, acute gastric dilation should be considered, especially in patients with an eating disorder (1).
The authors state that they have no Conflict of Interest (COI).

\section{Reference}

1. Kimura A, Masuda N, Haga N, et al. Gastrojejunostomy for pyloric stenosis after acute gastric dilatation due to overeating. World $\mathrm{J}$ Gastroenterol 21: 1670-1674, 2015.

The Internal Medicine is an Open Access article distributed under the Creative Commons Attribution-NonCommercial-NoDerivatives 4.0 International License. To view the details of this license, please visit (https://creativecommons.org/licenses/ by-nc-nd/4.0/).

(C) 2018 The Japanese Society of Internal Medicine Intern Med 57: 2267-2268, 2018 